\title{
A EXPERIÊNCIA DO MOVIMENTO CAMPONÊS SEM-TERRA NA EDUCAÇÃO POPULAR EM IVINHEMA-MS
}

\section{The experience peasant movement without land in Education Popular in Ivinhema-MS}

\author{
Thiago da Silva Melo \\ Mestrando em Geografia na Universidade Estadual de Londrina \\ thiago dasilvamelo@yahoo.com.br
}

Artigo recebido em 12/03/2016 e aceito para publicação em 27/06/2016

DOI: $10.12957 /$ tamoios.2016.21981

Resumo A educação é uma das principais vias de luta promovidas pelos movimentos sociais no campo, que se orienta a partir de concepções político-pedagógicas com a finalidade de dinamizar as relações dos sujeitos para a formação de condições da vida social. Nesse sentido, o movimento camponês exerce função fundamental na educação, mesmo naquela concebida como informal, através de seus saberes e vivências que expressam o exercício da liberdade e autonomia. $\mathrm{O}$ presente artigo objetiva apresentar e discutir questões sobre a educação do popular e a do campo, tendo como enfoque as experiências no Acampamento Irmã Dorothy Stang no município de Ivinhema-MS. Como metodologia, foi feito levantamento bibliográfico e realizadas entrevistas e observações no acampamento no decorrer dos anos de 2014 e 2015.

Palavras-chave: Movimento camponês. Educação do campo. Educação popular. Acampamento Irmã Dorothy Stang.

Abstract Education is one of the main thoroughfares fight promoted by social movements in the field, which is oriented from political-pedagogical concepts for strengthening relations of the subjects for the formation conditions of social life. In this sense, the peasant movement plays a key role in education, even then conceived as informal, through their knowledge and experiences that express the exercise of freedom and autonomy. This article aims to present and discuss issues on education and popular field with focus experiences at Camp Sister Dorothy Stang in the municipality of Ivinhema-MS. The methodology was made literature and conducted interviews and observations in the camp over the years 2014 and 2015.

Keywords: Peasant movement; Rural education; Popular education; Camp Sister Dorothy Stang. 


\section{INTRODUÇ̃̃OO}

As transformações na estrutura produtiva do Brasil, que passou da predominância da produção agrícola para a industrial, nas últimas décadas, promoveram diversas mudanças no espaço rural devido, principalmente, à mecanização e saída em extensão de pessoas do campo.

A lógica de produção passou a ser estabelecida pelo capital por meio das monoculturas na tentativa de homogeneização e eliminação das contradições, tanto do ponto de vista produtivo quanto dos conflitos sociais no campo, tendo reflexos, inclusive, nos modelos educacionais, que passaram a incidir estes interesses dominantes.

Como consequência da expansão do capital no campo, houve uma emigração em ampla quantidade de camponeses ${ }^{1}$, expulsos de suas terras, para as cidades, fazendo com que diversos estudiosos assegurassem que o campesinato desapareceria e que a única via seria a modernização nos padrões em que foi implementada. (KAUTSKY, 1980)

Nada obstante a essas conjecturas que decretaram o desaparecimento do campesinato, o que ocorreu foi um processo de (re) criação camponesa, que fez com que esta classe social garantisse sua manutenção por intermédio de suas características inerentes: mão de obra baseada no trabalho familiar, produção voltada para o autoconsumo, redes de cooperação e ajuda mútua, fizeram com que o campesinato sobrevivesse mesmo frente ao avanço do capital. (ALMEIDA, 2006)

Por conseguinte, o projeto do capital para o campo esbarrou na resistência do movimento camponês e na sua luta para a construção de um novo modelo de sociedade e de educação que preze pelo fortalecimento da democracia e da justiça social em seus sentidos mais amplos.

Portanto, os movimentos sociais no campo passam a reivindicar uma educação norteada pelos princípios de autonomia, liberdade e emancipação humana como projeto social, que se desdobraram na proposta da educação do campo:

Tendo sua origem no processo de luta dos movimentos sociais para resistir à expropriação de terras, a educação do Campo vincula-se à construção de um modelo de desenvolvimento rural que priorize os diversos sujeitos sociais do campo, isto é, que se contraponha ao modelo de desenvolvimento hegemônico que sempre privilegiou os interesses dos grandes proprietários de terra no Brasil, e também se vincula a um projeto maior de educação da classe trabalhadora, cujas bases se alicerçam na necessidade da construção de um outro projeto de sociedade e de Nação. (MOLINA E FREITAS, 2011, p. 19)

A educação do campo agrega atividades culturais, atividades de trabalho cotidianas dos sujeitos sociais e as estratégias de socialização, na tentativa de manter a identidade como 
elemento central no seu processo de reprodução social; por consequência, a educação está na perspectiva de luta dos movimentos sociais no campo com o objetivo de contribuir com um novo modelo de sociedade.

O modelo da educação do campo confronta o padrão "civilizatório", introduzido nas escolas com a modernidade, com experimentos pedagógicos diferenciados, colocando-se como um projeto de educação popular:

Tendo por sujeitos políticos coletivos os movimentos sociais populares, a educação do campo que reivindicam e os experimentos pedagógicos que realizam não poderiam ser identificados senão como educação popular (RIBEIRO, 2013, p. 43)

A educação do campo e a popular sinalizam para a mesma direção, uma vez que ambas buscam negar e questionar a estrutura social imposta e possibilitar meios para a transformação dos oprimidos em sujeitos sociais e ativos, com a possibilidade de decidir a respeito de qualquer assunto relacionado a sua vida. (PAIVA, 1984)

Mediante a educação popular e do campo, os camponeses demonstram sua organização e identidade de classe, demonstrando o papel político que os sujeitos precisam assumir para a transformação a partir da organização:

A dimensão educativa, formadora das classes populares, pode ser captada no processo histórico de organização dos movimentos sociais populares. Entendemos as formas através das quais os trabalhadores e trabalhadoras se organizam, dando origem aos movimentos sociais populares, enquanto sujeitos políticos coletivos de transformação social e de educação popular, conferem conteúdo a essa realidade histórica e social. (RIBEIRO, 2013, p. 46)

O campesinato se organiza em iniciativas significativas pela implantação e consolidação de práticas educativas que ultrapassem as limitações inerentes à educação formal, concebida pela classe dominante conforme já evidenciara Paulo Freire:

A prática educativa, reconhecendo-se como prática política, se recusa a deixarse aprisionar na estreiteza burocrática de procedimentos escolarizantes. Lidando com o processo de conhecer, a prática educativa é tão interessada em possibilitar o ensino de conteúdos às pessoas quanto em sua conscientização (FREIRE, 2001, p. 28)

O trabalho em questão traz relato e discussão teórica e política sobre a experiência educacional no âmbito rural no Acampamento Irmã Dorothy Stang, no município de IvinhemaMS. Sendo resultado de uma pesquisa que tem por objetivo contribuir para reflexões sobre práticas educativas alternativas às tradicionais.

Um dos aspectos primordiais observados durante o processo de investigação científica para a elaboração do artigo foi a metodologia empregada. Segundo Nossa (2005), esta etapa se 
compreende como um processo interligado de procedimentos, convergentes na problemática do acesso, tratamento e emprego dos dados e informações.

Foram feitos estudo bibliográfico e levantamento de informações por meio de pesquisa em periódicos especializados na temática, livros e trabalho de campo no acampamento, com a realização de entrevistas junto a lideranças do movimento e acampados no decorrer dos anos de 2014 e 2015.

A importância do estudo bibliográfico está no auxílio ao delineamento e delimitação do tema da pesquisa, da seleção adequada de bases de dados bibliográficos, no uso apropriado dos conceitos e suas definições e da síntese para a escolha das obras que integram a pesquisa. (PIZZANI et al., 2012)

A leitura de obras que abordam a educação do campo e a popular foram relevantes na compreensão das diversas questões que serão debatidas no decorrer do artigo, formando o arcabouço teórico de sustentação das argumentações e proposições que serão apresentadas.

O trabalho de campo constitui parte importante da averiguação, sendo uma atividade realizada pelo pesquisador no local onde o fenômeno estudado ocorre, consistindo na coleta e registro de dados, entrevistas e informações relativas ao objeto de estudo. (ALENTEJANO e ROCHA-LEÃO, 2006)

Sua realização permitiu a observação da experiência educacional vivenciada no acampamento da maneira que ocorreu a efetivação dessa iniciativa e como as teorias da educação do campo se materializam na realidade.

Foram entrevistadas dez pessoas entre as trinta e cinco acampadas, sendo duas autoridades do movimento e oito acampados, indicados pela liderança conforme o grau de envolvimento no projeto educacional desenvolvido. O tipo de entrevista utilizada foi a semiestruturada por atender as necessidades da pesquisa.

\section{A EDUCAÇÃO SEGUNDO OS CAMPONESES}

Os problemas e contradições históricas do espaço agrário do Brasil ultrapassam os limites dos assentamentos e acampamentos dos sem-terra para entrar na pauta de reivindicações do movimento camponês mundial representado pela Via Campesina ${ }^{2}$, e a educação no campo não poderia deixar de estar presente nas pautas reivindicatórias dos movimentos sociais do campo.

Através das lutas dos movimentos sociais, a educação do campo tem como finalidade romper com a concepção de trabalhador rural que durante décadas foi construída e consolidada 
pela Educação elitista, que considera ser natural os sujeitos do campo serem considerados como atrasados, inferiores; que a condição de pobreza seja seu destino inevitável; que, no campo, não haja escola, que seja necessário se deslocar até a cidade para frequentar uma escola; que o acesso à educação seja restrito à escola, que os saberes e conhecimentos produzidos pelos camponeses sejam desqualificados e considerados como ignorância. Nesse sentido, Oliveira faz a seguinte afirmação:

Lutar por uma educação de qualidade, ligada à organização de classe, é desafiar o poder da dissolução da escola e do sistema educativo, e construir um novo sistema ligado à cultura dos trabalhadores camponeses e de suas comunidades. Esta tomada de consciência por parte dos movimentos sociais no campo brasileiro ocorre diante da realidade educacional presente nas escolas. (OLIVEIRA, 2010, p. 53)

Nesse contexto de luta por um modelo de educação que seja popular, os membros do Acampamento Irmã Dorothy Stang se uniram para construir uma escola na qual as crianças tivessem a oportunidade de aprender mais sobre a cultura camponesa.

O Acampamento se localiza próximo às margens da BR 376, perto da entrada da cidade de Ivinhema-MS (Figura 1).

Figura 1 - Localização do Acampamento Irmã Dorothy Stang no município de Ivinhema-MS

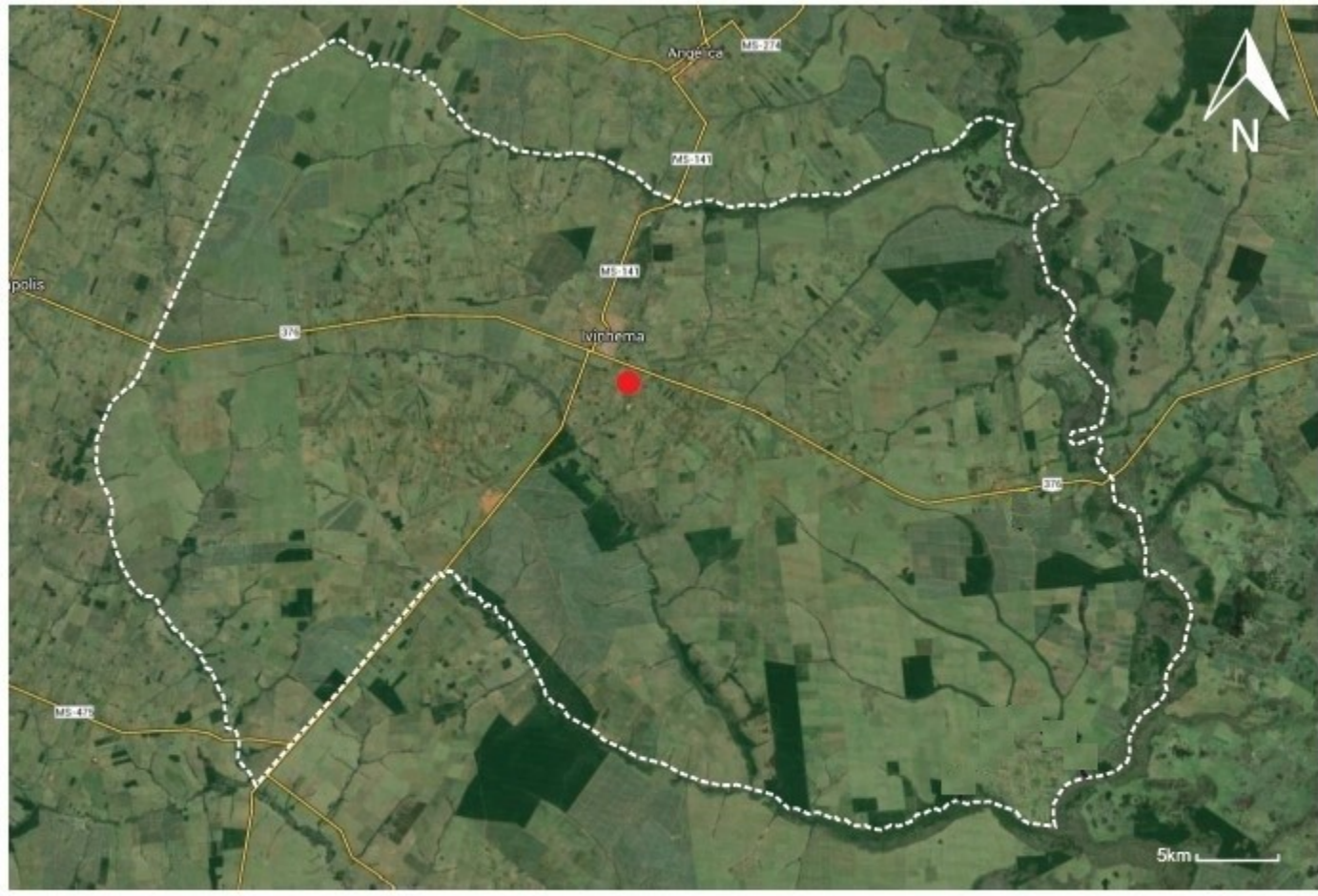

Legenda

Acampamento Irmã Dorothy Stang 
A ocupação teve início em 2003 quando trabalhadores rurais sem-terra, que exerciam a atividade de boias-frias oriundos, principalmente, da periferia da cidade, se uniram na luta pela a realização do sonho de terem sua prória terra para cultivar e dar melhores condições de vida as suas famílias.

São trinta e duas famílias acampadas em um espaço insufuciente de vinte e cinco metros quadrados, cedido pela prefeitura após muita luta e negociação dos acampados, depois de terem sido despejados de outra área que ocuparam até o ano de 2012.

Atualmente, estão filiados ao Departamento Estadual dos Trabalhadores Rurais da Central Única dos Trabalhadores (DETR-CUT). Essa organização sindical:

Para alcançar seus objetivos em relação à luta pela terra, a CUT-MS tem como tática de luta: consolidar uma organização estadual da agricultura familiar do Mato Grosso do Sul, que lute pela Reforma Agrária e pela construção do projeto alternativo de desenvolvimento rural sustentável e solidário. (SILVA, 2004, p. 62)

Na perspectiva da luta pela Reforma Agrária e construção de um projeto alternativo frente o avanço do capital no campo, os acampados formaram uma escola informal para as crianças desenvolverem atividades. (Figuras 3 e 4 )

Figuras 3 e 4: Escola do Acampamento Irmã Dorothy Stang

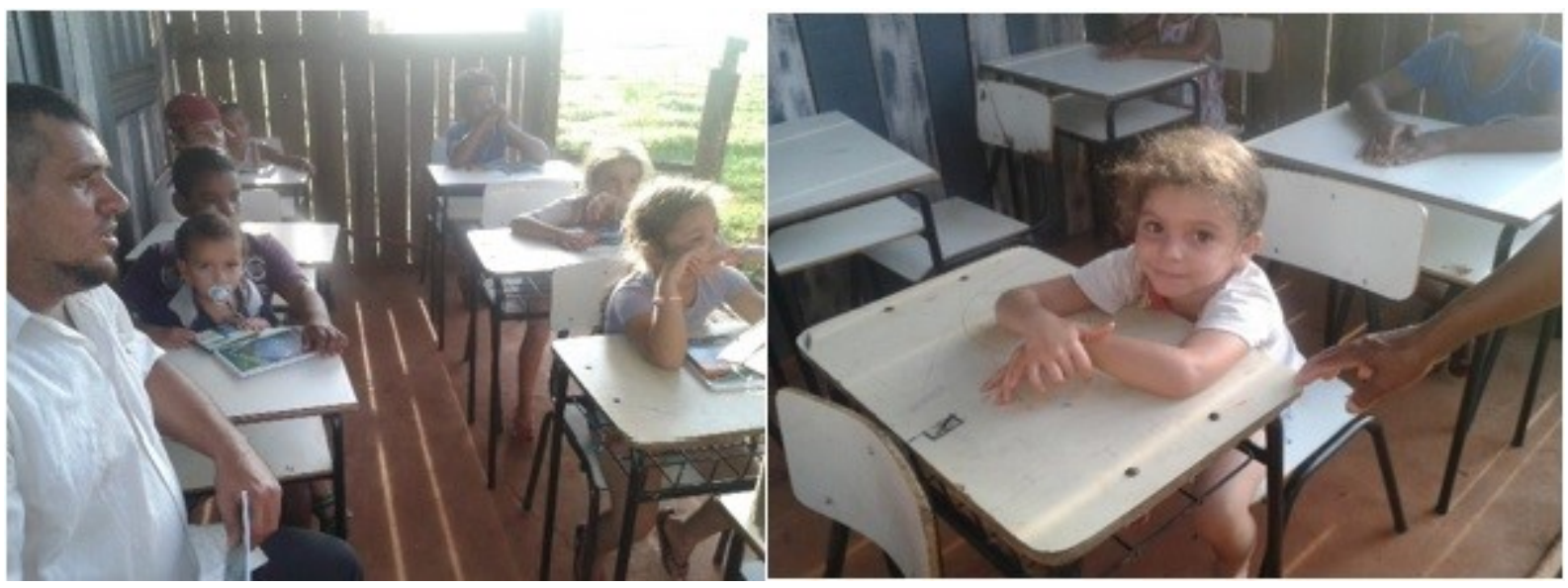

Fotos: Thiago da Silva Melo.

Cerca de quinze crianças frequentam a escola do acampamento; o número oscila, pois visitantes também são recebidos. A faixa etária das crianças alterna entre dois e dez anos de ambos os sexos.

As atividades desenvolvidas são bastante diversas e vão desde a criação e pintura de desenhos sobre a questão agrária, o aprendizado de cantigas do movimento sem-terra e gritos de guerra pela Reforma Agrária. 
As aulas são realizadas aos fins de semana com a colaboração de todos os acampados, o modelo utilizado no acampamento para o ensino das crianças está no âmbito da educação informal; segundo Gohn:

A educação informal "aborda processos educativos que ocorrem fora das escolas, em processos organizativos da sociedade civil, ao redor de ações coletivas do chamado terceiro setor da sociedade, abrangendo movimentos sociais, ONGs e outras entidades sem fins lucrativos que atuam na área social; ou processos educacionais frutos da articulação das escolas com a comunidade educativa, via conselhos, colegiados, etc." (2008, p. 7)

Ainda segundo Gohn (2005), a educação informal pode ser resumida em: processo de aprendizagem gerado através da experiência de contato com as fontes; aprendizagem decorrente das repetições de ações rotineiras; apreensão e aprendizagem das diferenças existentes na realidade social; aprendizagem gerada pelo contato com o movimento; aprendizagem da desmistificação da autoridade como sinônimo de competência, a qual, sinônimo de conhecimento.

Na concepção de Brandão (1985), a educação informal está relacionada com o processo "livre" de transmissão de certos saberes, tais como a fala comum a um dado grupo das tradições culturais e demais comportamentos característicos da comunidade.

Os elementos que compõe a educação informal permitem uma abordagem mais livre das temáticas apresentadas às crianças, já a educação formal apresenta diversos fatores que seriam limitadores:

Quanto à educação formal, ela geralmente se parece mais com uma forma de adestramento, disciplinarização, treinamento e docilização dos indivíduos, do que como meio de transformação e de revolução social. Mesmo quando tem a preocupação de ser crítica, de subverter a ordem acadêmica e de questionar o sistema vigente, o que é um tanto raro e incomum nos tempos atuais, é envolvida por um amplo aparato disciplinar e burocrático deixando pouco espaço para flexibilidade e para a realização de experiências alternativas (OLIVEIRA, 2010, p. 51).

A educação formal, dessa forma, é obstaculizada pela elite, pois o sistema educacional foi criado para atender as demandas da classe burguesa, bem como para justificar e defender seus ideais. Dessa forma, para a classe trabalhadora, restou apenas ser disciplinada nos moldes desta ideologia até então.

Segundo uma das líderes do acampamento, Débora Lima ${ }^{3}$, a formação da escola foi importante para as crianças conhecerem a luta pela terra e a Reforma Agrária, entendendo o espaço onde moram; contribuindo assim para a formação social dos sem-terrinha: 
A educação é um processo de formação do ser, ou seja, é através dela que a luta pela Reforma Agrária e pelos demais objetivos do movimento podem permanecer nos Sem-Terrinha. É educando que a luta, para os militantes, continuará. (OLIVEIRA, 2010, p. 77)

Levando em consideração seus diferentes estágios de desenvolvimento, devido às faixas etárias variadas, a finalidade do ensino é a formação política desde a infância para que as crianças compreendam o significado da luta pela terra de seus pais, e que estes, certamente, continuarão.

As crianças são estimuladas a aprender por meio de cantigas que são entoadas em conjunto, desenhos, pinturas e brincadeiras que objetivam despertar o interesse e a curiosidade delas sobre a temática.

As atividades estimulam as crianças a aprender em grupo, contribuindo para o avanço de sua condição humana, já que as pessoas não aprendem ser humanas sozinhas; ajudando as crianças enraizarem-se em coletividades fortes, potencializando o convívio social, humano, na construção de suas identidades, conhecimentos, sentimentos e valores. (CALDART, 2000)

Por intermédio da educação e vivência no movimento, os sujeitos criam o sentimento de ser Sem-Terra; o movimento cria a partir da educação uma identidade atribuída ao camponês que luta não apenas por uma terra para si, mas para todos, por participar e defender os direitos da coletividade.

O convívio e a construção coletiva do conhecimento também contribuem para a formação política das crianças:

Os movimentos que se estruturam a partir de objetivos táticos e estratégicos caminham para formar a organização política de sua força e a constituição de sua classe social, como é o caso dos trabalhadores sem-terra que, ao se organizarem, entram para a classe camponesa. (BOGO, 2008, p. 100).

Débora Lima também afirmou que a escola, ainda que informal, é importante para que a criança relate aos colegas, no convívio escolar (educação formal), suas experiências no acampamento e transmita, em sua linguagem, os significados da luta pela terra, buscando desconstruir diversos estigmas e preconceito sobre os sem-terra e afirmando a identidade coletiva, uma vez que a criança camponesa pouco ou não se vê representada, quando não desvalorizada, no sistema formal de ensino.

O aprendizado por parte dos pequenos não se retringe aos conhecimentos adquiridos na escola, sendo sua vivência no acampamento um processo de contínua aprendizagem das práticas culturais 
Essas práticas culturais devem ser entendidas como a repetição e manutenção de comportamentos e a transmissão de modos de agir, seja pelo ensino ou pela observação do indivíduo; dessa forma, novas gerações aprendem práticas culturais de gerações anteriores.

Por meio da observação, identificam elementos da cultura camponesa como a essência solidária, onde dar, receber e retribuir, é um dos sentidos de ser e viver, convivendo e respeitando o próximo:

As pessoas se educam nas ações porque é o movimento das ações que vai conformando o jeito de ser humano. As ações produzem e são produzidas através de relações sociais: ou seja, elas põem em movimento um outro elemento pedagógico fundamental que é o convívio entre as pessoas, a interação que se realiza entre elas, mediada pelas ferramentas herdadas de quem já produziu outras ações antes (cultura); nestas relações as pessoas se expõem como são, e ao mesmo tempo vão construindo e revisando suas identidades, seu jeito de ser. (CALDART, 2000, p. 54)

Os alunos veem o resgate de valores como união e solidariedade por meio de atitudes dos acampados como a construção de um brechó para arrecadar roupas para as pessoas que precisam e um albergue para abrigar pessoas que estejam enfrentando alguma dificuldade temporária no acampamento.

No contato com os adultos, as crianças aprendem por intermédio da oralidade, que assume um papel fundametal para a cultura camponesa, e também por meio das narrativas de histórias que trazem à tona sua memória e mesmo seus mitos:

À primeira vista, as narrativas e os registros memoriais fragmentados parecem pouco relevantes para o estudo do social. Porém, pela reiteração dos elementos constitutivos dos encantamentos, as histórias contadas revelam uma "realidade vivida e sentida pelos homens em sociedade". Sem contestar as propriedades universais do mito, os relatos míticos encontrados trazem, para o plano real, um universo repleto de personagens sobrenaturais escondidos embaixo da terra ou nas águas subterrâneas, sobretudo nos poços e nos olhos d'água: as almas e demais aparições ocupam o território, lembrando aos vivos que há uma presença anterior, demarcando espaços com sinais, pedras, "letreiros" e cruzes. Assim, o mito transforma-se em memória. Pois, no fim das contas, aparece como a única lembrança dos acontecimentos que marcaram a vida dos antepassados. (GODOI et al, 2009, p. 72)

Podemos refletir que um dos mecanismos de educação no acampamento é o compartilhamento de significados e ferramentas de cultura, auxiliando na tarefa de significação das ações dos sujeitos sociais, transformando-os em valores, convicções, costumes, comportamentos, símbolos e gestos de seu modo de vida refletido na coletividade da qual fazem parte. 
Isto quer dizer, entre outras coisas, que educar as pessoas é ajudar a cultivar sua memória, é conhecer e reconhecer seus símbolos, gestos, palavras; é situá-las num universo cultural e histórico mais amplo, é trabalhar com diferentes linguagens, é organizar diferentes momentos e feitos para que as pessoas reflitam sobre suas práticas, suas raízes, seu projeto, sua vida... (CALDART, 2003, p. 55)

No acampamento, há uma grande diversidade de cultivos: mandioca, milho, feijão, cebolinha (figuras 5 e 6), e as crianças também aprendem a plantar e a lidar com a terra, produzindo o próprio alimento.

Figuras 5 e 6 - Cultivos no acampamento.

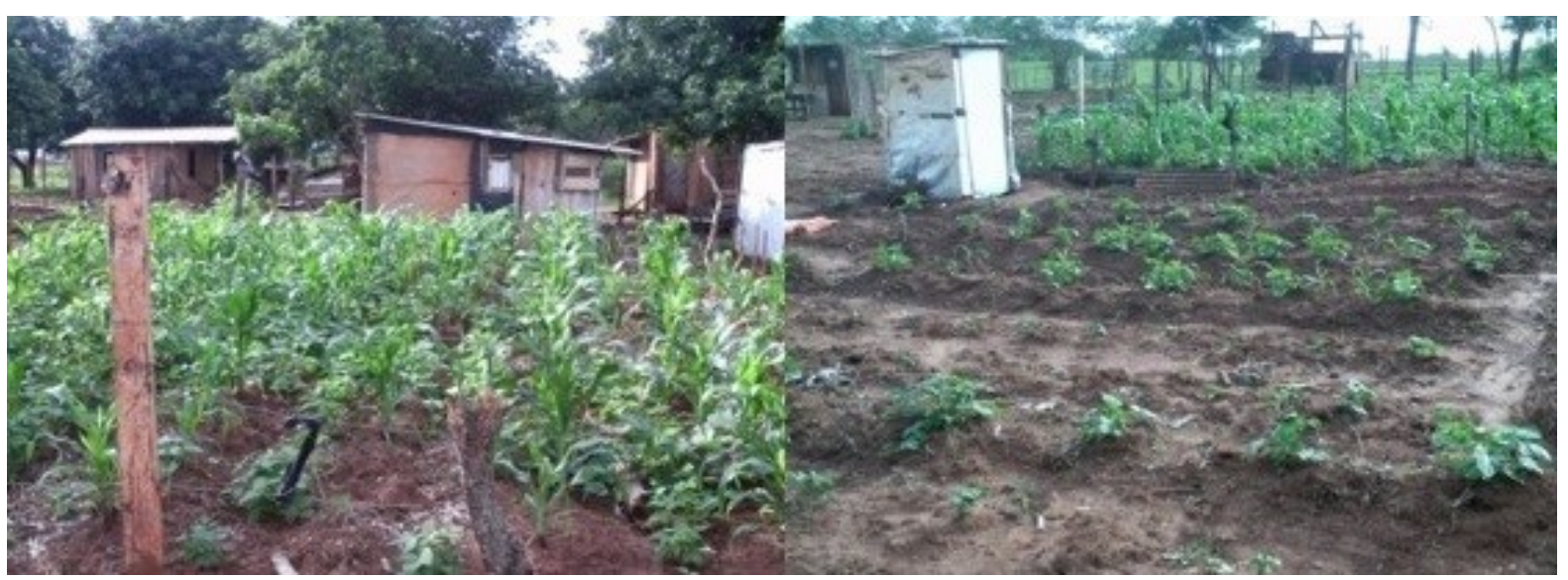

Fotos: Thiago da Silva Melo.

Dessa forma, as crianças aprendem na prática por intermédio de seu trabalho com a relação que estabelecem com a natureza e consigo:

Pensamos o trabalho na sua dimensão educativa que, pela relação que o trabalhador estabelece com a natureza, mediada pelas relações consigo mesmo e com outros trabalhadores, humaniza enquanto produz bens materiais, imateriais, linguagem, arte, conhecimento e cultura. (RIBEIRO, 2013, p. 44)

Outros conhecimentos sobre a natureza vão sendo construídos devido o contato com os adultos e suas observações, estabelecendo uma relação bastante peculiar com a natureza, que é um dos elementos da cultura camponesa:

Uma relação particular com a natureza também é verificada entre os camponeses no conhecimento que possuem sobre o clima, calendário agrícola para planejar a produção, manejos e semeadura feitos levando em consideração o calendário lunar, enfim os astros. (PAULINO e FABRINI, 2008, p. 263)

A escola no acampamento, ainda que informal, tem um papel fundamental na formação das crianças, iniciando o processo de criação identitária e raízes camponesas por percorrerem diferentes momentos, situações, trajetórias e contextos acerca do cotidiano onde residem. 
Trazendo lições pedagógicas com suas práticas voltadas à formação humana, política e cultural dos sujeitos, fazendo um contraponto reflexivo à educação institucionalizada.

\section{CONSIDERAÇÕES FINAIS}

A educação do campo foi idealizada em uma esfera de luta dos movimentos sociais do campo, sendo uma concepção político pedagógica com a finalidade de dinamizar a relação dos seres humanos com a geração de condições de vida social.

Os camponeses organizam-se em movimentos sociais populares, criando alternativas de sociedade e de educação, as quais pressupõem um processo de emancipação social.

Tomamos como exemplo as experiências no Acampamento Irmã Dorothy Stang para evidenciar a importância da educação voltada para a formação da identidade coletiva do indivíduo e valorização dos elementos de sua cultura, que passa a ser ensinada de forma dinâmica pelos próprios camponeses.

A escola no acampamento analisado articula trabalho e educação dentro de um projeto popular de sociedade, tomando como princípio e finalidade da formação humana a liberdade, a autonomia e a emancipação.

Isto posto, o artigo mostrou, a partir das experiências no acampamento estudado, a importância de uma educação popular voltada para o ensino da cultura camponesa a partir da vivência dos próprios sujeitos, contribuindo para os estudos relacionados à educação do campo, ciente de que esta é apenas uma pequena contribuição que necessita ser aprofundada junto a maiores estudos e pesquisas sobre a temática.

\section{NOTAS}

1 O conceito de camponês é utilizado em detrimento ao de agricultor familiar por compreendermos o campesinato enquanto classe social e modo de vida. A respeito, consultar: Almeida (2006); Godoi et al (2009); Paulino e Fabrini (2008) e Ribeiro (2013).

${ }^{2}$ A Via Campesina é um movimento internacional que coordena organizações camponesas de pequenos e médios agricultores, trabalhadores agrícolas, mulheres rurais e comunidades indígenas e negras da Ásia, África, América e Europa. Uma das principais políticas da Via Campesina é a defesa da soberania alimentar. Este movimento não se opõe ao comércio agrícola, desde que as condições acima enunciadas sejam respeitadas, em particular para aqueles produtos que necessitem de condições climáticas específicas. Para a Via Campesina, a biodiversidade tem como base fundamental o reconhecimento da diversidade humana, a aceitação de que somos diferentes e de que cada povo e cada pessoa têm liberdade para pensar, para ser e agir.

${ }^{3}$ Débora Lima é uma das líderes do acampamento e integrante do movimento desde o final dos anos 2000. O projeto de educação popular e do campo foi idealizado e implementado por ela. 


\section{REFERÊNCIAS}

ALBERTI, Verena. "Histórias dentro da história. " In: PINSKY, Carla (org.). Fontes históricas. São Paulo, Contexto, 2005, p.155-202.

ALENTEJANO, Paulo Roberto Raposo; ROCHA-LEÃO, Otavio Miguez da. Trabalho de campo: uma ferramenta essencial para os geógrafos ou um instrumento banalizado? In: Boletim Paulista de Geografia, Presidente Prudente, v. 84, p. 51-67, 2006.

ALMEIDA, Rosemeire Aparecida de. (Re) criação do campesinato, identidade e distinção: a luta pela terra e o habitus de classe. São Paulo: UNESP, 2006.

BOGO, Ademar. Identidade e luta de classes. São Paulo: Expressão Popular, 2008.

BRANDÃO, Carlos Rodrigues. O que é educação. São Paulo: Abril Cultura; Brasiliense, 1985.

CALDART, Roseli Salete. Pedagogia do Movimento Sem Terra, Petrópolis: Vozes, 2000.

. Movimento sem-terra: lições de pedagogia. In: Currículo sem Fronteiras, v.3, n.1, pp. 50-59, Jan/Jun. 2003.

FREIRE, Paulo. Política e Educação: ensaios. 6. ed. São Paulo: Editora Cortez, 2001. (Coleção Questões da nossa Época, v. 23)

GODOI, Emília Pietrafesa de. [et al.] (org). Diversidade do campesinato: expressões e categorias, v. 1, São Paulo: Editora da UNESP, 2009.

GOHN, Maria da Glória. Educação não-formal e cultura Política: impactos sobre o associativismo no terceiro setor.4. ed. São Paulo: Cortez, 2008.

Teoria dos movimentos Sociais: paradigmas clássicos e contemporâneos. 2.

Ed. São Paulo: Edições Loyola, 2005.

KAUTSKY, Karl. A questão agrária. 3. ed. São Paulo: Proposta Editorial, 1980.

MARTINELLO, André Souza. O trabalho de saber: cultura camponesa e escola rural. In: Revista Campo-Território: revista de geografia agrária, v.3, n. 5, p. 291-295, fev. 2008.

MOLINA, Mônica Castagna; FREITAS, Helana Célia de Abreu. Avanços e desafios na construção da Educação do campo. In: Revista Em Aberto, Brasília, v. 24, n. 85, p. 17-31, abr. 2011.

NOSSA, Paulo Nuno Maia de Sousa. Abordagem Geográfica da Oferta e Consumo de Cuidados de Saúde. Tese (Doutorado em Geografia) - Lisboa: Instituto de Ciências Sociais, Universidade do Minho, 2005.

OLIVEIRA, Mara Edilara Batista de. Terra, trabalho e escola: a luta do MST por uma educação do/no campo na Paraíba. Dissertação (Mestrado em Geografia). Centro de Ciências Exatas e da Natureza. UFPB, João Pessoa, 2010. 
PAIVA, Vanilda. (org.). Perspectivas e dilemas da educação popular. Rio de Janeiro: Graal, 1984.

PAULINO, Eliane Tomiasi; FABRINI, João Edmilson (Org). Campesinato e Territórios em Disputa. São Paulo: Expressão Popular, 2008.

PIZZANI, Luciana; Silva, Rosemary Cristina da; BELLO, Suzelei Faria; HAYASHI, Maria Cristina Piumbato Innocentini. A arte da pesquisa bibliográfica na busca do conhecimento. In: Revista Digital de Biblioteconomia e Ciência da Informação, Campinas, v. 10, p. 53-66, 2012 .

RIBEIRO, Marlene. Movimento camponês, trabalho e educação: liberdade, autonomia, emancipação: princípio/fins da formação humana. 2. ed. São Paulo: Expressão Popular, 2013.

SILVA, Tânia Paula da. As formas organizacionais de produção dos camponeses assentados no município de Batayporã-MS. Dissertação (Mestrado em Geografia). FCT. UNESP, Presidente Prudente, 2004. 